\title{
The Relevance of Francolin Vocalization in Local Time Indication in Mamfe Municipality, Southwest Region, Cameroon
}

\author{
Melle Ekane Maurice ${ }^{1 *} \quad$ Nasako Noto Penda ${ }^{1} \quad$ Manjo Chiara Keafon ${ }^{2}$ \\ Nkongho Stanley Ayamba ${ }^{2}$ Mbole Veronique ${ }^{2}$ \\ Department of Forestry and Wildlife, Faculty of Agriculture and Veterinary Medicine, University of Buea, \\ P.O. Box 63, Buea, Cameroon
}

\begin{abstract}
Avian vocalizations can have intra-specific and inter-specific functions such as communication alarm, resource location, pair-bond maintenance, territory defense, and mate attraction. Majority of studies have focused on the diurnal vocalization of birds. Very little research has been done on nocturnal vocalization behavior of birds such as francolins in Cameroon. For this reason, this study was aimed at assessing the importance of francolin vocalization in local time indication to the inhabitants of Mamfe municipality. The data collection method of this study comprised of random spot sampling of the francolin number, recording vocalizations in the dawn and dusk, and visiting the francolin nesting sites. Surveys were conducted 5 days per week, from Monday to Friday for a period of one month. In the dawn, call recording started 7:00am and ended 5:00pm, while in the dusk it started 7:00 pm and ended 6:00am. This study revealed a significant association between francolin number and the dayperiod, $\chi^{2}=19.219 \mathrm{df}=6 \mathrm{P}=0.004$. Vocalization time and frequency showed a significant link, $\chi^{2}=6.834 \mathrm{df}=8$ $\mathrm{P}<0.05$. Similar results were obtained from the association of bird number and vocalization frequency, $\chi^{2}=21.294$ $\mathrm{df}=4 \mathrm{P}=0.000$. The bird number was proportionate to call frequency and intensity, 5 birds and above generated a call frequency of $64.79 \%$. The day-period and bird number associated significantly, $\chi^{2}=51.278 \mathrm{df}=44 \mathrm{P}<0.05$. Additionally, cropland vegetation showed a significant correlation on bird number, $r=0.244 \mathrm{P}<0.05$. Furthermore, the bird group-size witnessed an influence on the call location, with more calls from cropland $(70.42 \%)$ than the forest vegetation $(29.58 \%)$. The consistent vocalization frequency during the early hours of the morning period is useful to the local inhabitants of the municipality. Almost all the local crop-farmers interviewed acknowledged that the francolin vocalization were time-specific, hence, reminding them upon the preparation of early morning farming engagements. Moreover, it is believed in most part of Cameroon, especially in remote communities that the francolin vocalizations help to wake up local farmers from sleep during the early of the day. However, the declining population of this bird species raises many questions on its conservation.
\end{abstract}

Keywords: Francolin vocalization, Communication alarm, Bird number, Cropland vegetation

DOI: $10.7176 / \mathrm{CER} / 12-9-03$

Publication date:September $30^{\text {th }} 2020$

\section{INTRODUCTION}

The francolins belong to the order Galliformes, which includes the true terrestrial land game birds. The order is characterized by having strong well-built legs, a chicken-like heavy body with comparatively long legs having spurs, all suited for efficient movement on the ground, and blunt and rounded tail and wings (Pomeroy and Abe, 1992). The order represents a large and diverse group, comprising of 70 genera and 250 species (Payne, 2000; Dickinson, 2003), which have been grouped into six families, viz., Numididae (guineafowl), Phasianoidae (pheasants, quails), Odontophoridae (New world quails), Cracidae (chachalacas, curassows and grouse), Megapodiidae (megapodes) and Phasianidae (Johnsgard, 1999; Dickinson, 2003). The members of family Phasianidae are distributed in diverse habitats, like, rainforests, scrub forests, deserts, woodlands, bamboo thickets, cultivated lands, alpine meadows, tundra and forest edges. The members of the family have short toes with blunt claws, the raised hallux and crest or bare skin on the head (Madge and McGowan, 2002). The Phasianids are mainly cursorial, depending mainly on walking, though some can fly efficiently for short distances. They find their food by digging or scratching the ground and use dust bathing (Johnsgard, 1999; Islam, 1999). Genus Francolinus is represented by some 41 species which are distributed in different parts of the world.

The distinction between songs and calls in francolin birds is based upon complexity, length, and context. Songs are longer and more complex and are associated with courtship and mating, while calls tend to serve such functions as alarms or keeping members of a flock in contact (Ehrlich, et al 2008). Other authorities such as Howell and Webb (1995) make the distinction based on function, so that short vocalizations, such as those of pigeons, and even non-vocal sounds, such as the drumming of woodpeckers and the "winnowing" of snipes' wings in display flight, are considered songs (Howell, et al. 1995). Still others require song to have syllabic diversity and temporal regularity akin to the repetitive and transformative patterns that define music. It is generally agreed upon in birding and ornithology which sounds are songs and which are calls, and a good field guide will differentiate between the two. Bird song is best developed in the order Passeriformes. Some groups are nearly voiceless, producing only 
percussive and rhythmic sounds, such as the storks, which clatter their bills. In some manakins (Pipridae), the males have evolved several mechanisms for mechanical sound production, including mechanisms for stridulation not unlike those found in some insects (Howell,et al 2005).

Song is usually delivered from prominent perches, although some species may sing when flying. The production of sounds by mechanical means as opposed to the use of the syrinx has been termed variously instrumental music by Charles Darwin, mechanical sounds (Manson-Barr, and Pye, 1985) and more recently sonation (Bostwick et al 2003). The term sonate has been defined as the act of producing non-vocal sounds that are intentionally modulated communicative signals, produced using non-syringeal structures such as the bill, wings, tail, feet and body feathers (Bostwick et al 2003). In extratropical Eurasia and the Americas almost all song is produced by male birds; however in the tropics and to a greater extent the desert belts of Australia and Africa it is more typical for females to sing as much as males. These differences have been known for a long time (Hartshorne 1958) and are generally attributed to the much less regular and seasonal climate of Australian and African arid zones requiring that birds breed at any time when conditions are favorable, although they cannot breed in many years because food supply never increases above a minimal level. With a seasonal irregular breeding, both sexes must be brought into breeding condition and vocalization, especially duetting, serves this purpose. The high frequency of female vocalizations in the tropics, Australia and Southern Africa may also relate to very low mortality rates producing much stronger pair-bonding and territoriality (Slater and Mann (2004).

In some tropical bird species, mimics such as the drongos may have a role in the formation of mixed-species foraging flocks (Goodale \& Kotagama, 2005). Vocal mimicry can include con-specifics, other species or even man-made sounds. Many hypotheses have been made on the functions of vocal mimicry including suggestions that they may be involved in sexual selection by acting as an indicator of fitness, help brood parasites, or protect against predation, but strong support is lacking for any function (Kelley et al 2008). Many birds, especially those that nest in cavities, are known to produce a snakelike hissing sound that may help deter predators at close range (Marler \& Hans 2004). Some cave-dwelling species, including the oilbird (Suthers \& Hector 1985), and swiftlets (Collocalia and Aerodramus spp.) (Suthers \& Hector 1982), use audible sound (with the majority of sonic location occurring between 2 and $5 \mathrm{kHz}$ (Coles et al 1987 ) to echolocate in the darkness of caves. The only bird known to make use of infrasound (at about $20 \mathrm{~Hz}$ ) is the western capercaillie (Lieser et al 2005).

The hearing range of birds is from below $50 \mathrm{~Hz}$ (infrasound) to around $12 \mathrm{kHz}$, with maximum sensitivity between 1 and $5 \mathrm{kHz}$ (Møller et al 2005). The black jacobin is exceptional in producing sounds at about $11.8 \mathrm{kHz}$. It is not known if they can hear these sounds (Olson, et al 2018). The range of frequencies at which birds call in an environment varies with the quality of habitat and the ambient sounds. The acoustic adaptation hypothesis predicts that narrow bandwidths, low frequencies, and long elements and inter-element intervals should be found in habitats with complex vegetation structures (which would absorb and muffle sounds), while high frequencies, broad bandwidth, high-frequency modulations (trills), and short elements and inter-elements may be expected in open habitats, without obstructive vegetation (Derryberry 2009; Boncoraglio \& Nicola 2007; Morton, 1975).

Low frequency songs are optimal for obstructed, densely vegetated habitats because low frequency, slowly modulated song elements are less susceptible to signal degradation by means of reverberations. High frequency calls with rapid modulations are optimal for open habitats because they degrade less across open space (Ey, \& Fischer 2012; Tubaro, et al 1994). The acoustic adaptation hypothesis also states that song characteristics may take advantage of beneficial acoustic properties of the environment. Narrow-frequency bandwidth notes are increased in volume and length by reverberations in densely vegetated habitats (Slabbekoorn, et al 2002). It has been hypothesized that the available frequency range is partitioned, and birds call so that overlap between different species in frequency and time is reduced. This idea has been termed the "acoustic niche" (Krause 1993). Birds sing louder and at a higher pitch in urban areas, where there is ambient low-frequency noise (Henrik 2004; Slabbekoorn et al 2003). Traffic noise was found to decrease reproductive success in the great tit (Parsus major) due to the overlap in acoustic frequency (Halfwerk et al 2011). An increase in song volume restored fitness to birds in urban areas, as did higher frequency songs (Luther et al 2012).

Birds are considered to be ecologically important in environmental indication; however, much attention is not given to their protection in countries like Cameroon, rich in bird species and population, due to poor implementation of conservation policies. The importance of francolin birds such as Francolinus camerunensis, and Pternistis camerunensis in local time indication in Manfe municipality seems to be neglected due to their croppest behavior. Wildlife conservation is not very much welcome in most parts of Cameroon because the local inhabitants in wildlife habitat peripheral zones are forced into the conservation programs without any serious agreement and education. Hence, the aim of this study was to assess the significance of francolin vocalizations to the local inhabitants of Manfe municipality in local time indication.

\section{MATERIALS AND METHODS}

Description of the study area

Mamfe municipality is found in the Southwest Region of Cameroon between latitude $5^{0} 46^{\prime} 0^{\prime}$ ' north and longitude 
$9^{0} 17^{\prime} 0$ ', east (fig.1). Climatically, Manfe falls within the equatorial zone, it has the equatorial rain forest climate, which is characterized by two distinct seasons; the rainy and the dry seasons. The dry season runs from October/November to March and is characterized by elevated temperatures $\left(30^{\circ} \mathrm{C}-32^{\circ} \mathrm{C}\right)$ (Thomas 1988). The rainy season begins from March/April and ends in September/October with an annual average rainfall ranging between $3500 \mathrm{~mm}-4000 \mathrm{~mm}$, and peak periods in the months of July and August. Generally, the equatorial rain Forest occupies the area and it also falls within the tropical evergreen forest type of Cameroon. It is also part of the Guineo-Congolian floristic region with altitude ranging from $90 \mathrm{~m}-500 \mathrm{~m}$ above sea level. The variation in the above-mentioned characteristics causes the existence of two unique types of vegetation in the municipality. The vegetation types are the lowland rain forest and the mid-altitude forest. Mamfe municipality falls within the tropical evergreen rainforest zone of Cameroon. It is endowed with valuable forest resources including timber, non-timber forest products (NTFPs) and wildlife (Thomas 1988).

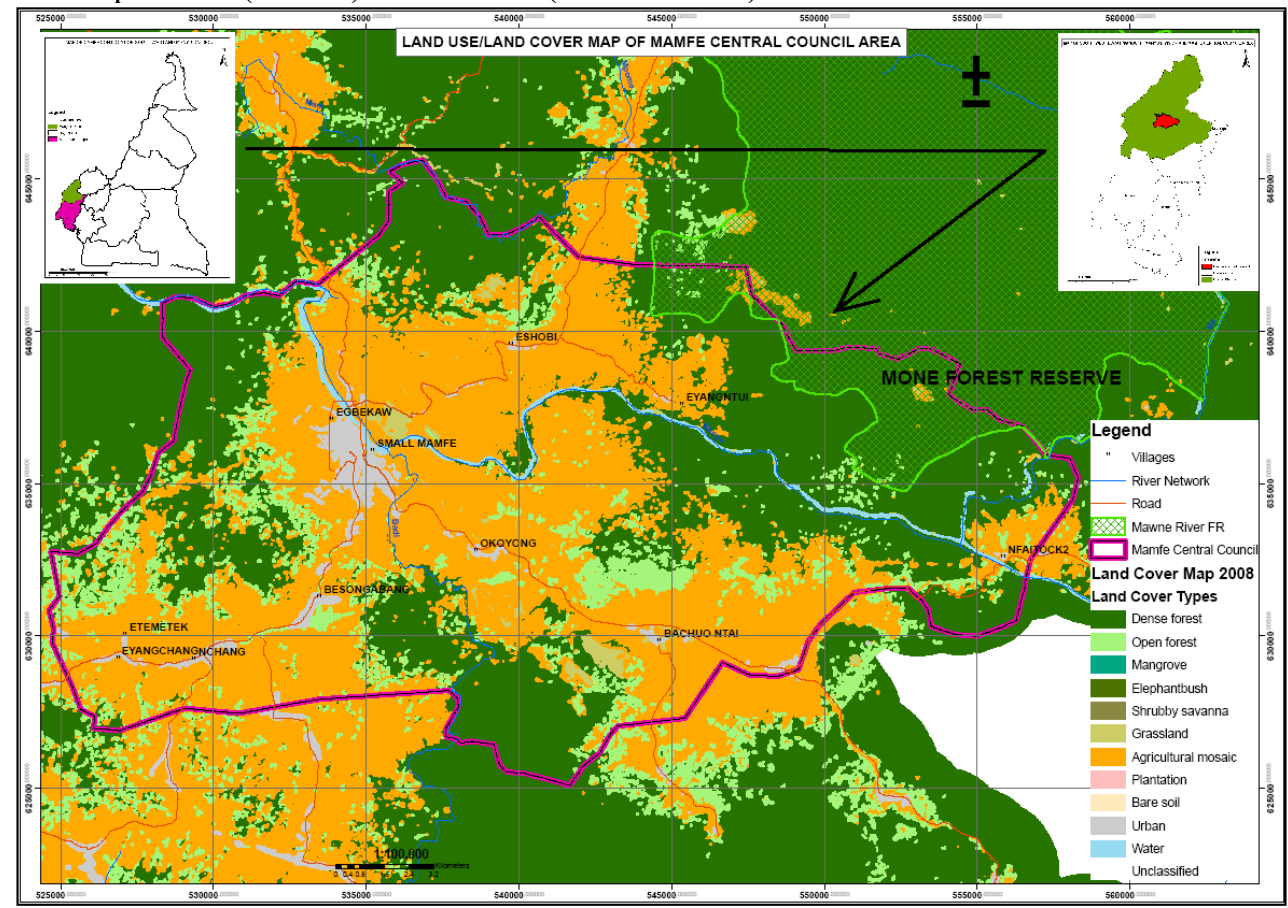

Figure 1: Map of Mamfe municipality (Source: Mamfe Council 2012)

\section{Data collection method}

The data of this survey was collected on check-sheets in the study area, Mamfe municipality. The brief pilot study witnessed the testing of research methods and familiarization of the research team with the community inhabitants and their norms. Most of the research team members were people from these communities, who volunteered to ensure the security of the principal investigator. Data collection was based on visiting farmlands, forest, and secondary forest during the dawn to records vocalizations, and visits were made to locations from where these calls were heard, this helped to estimate the number of francolin birds in the roosting sites and also the vegetation type (Buckland et al. 2004; Thomas et al. 2010). In the dusk, the research team members recorded vocalizations from their houses where they lodged for security reasons. Francolin calls were recorded randomly as were heard, but making sure the nearby call locations and vegetation types were noted. Surveys were conducted 5 days per week, from Monday to Friday for a period of one month. In the dawn, call recording started 7:00am and ended 5:00pm, while in the dusk it started 7:00 pm and ended 6:00am.

\section{Data Analysis}

The research data was analyzed by the use of SPSS version 20; chi-square and correlation statistical models considered most appropriate for the variables were used. The quantitative data such as the number of francolin birds and vocalization time were tested on atmospheric conditions and vegetation types. Additionally, both quantitative and qualitative variables such as francolin number, and vocalization locations were analyzed exploratory.

\section{RESULTS}

This study revealed a significant association between bird number and the day-period, $\chi^{2}=19.219 \mathrm{df}=6 \mathrm{P}=0.004$ (fig.2). Francolins, commonly called "bush fowl" are wildlife birds prominently important in many traditions because of their vocalizations. In most remote areas especially village communities, these birds serve for 
environmental time indication. In this research the bird number influenced the call frequency. Wildlife species are known to niche in territorial colonies, which consist of adults, sub-adults and juveniles. The social colonial life benefits the species defense against predators, location of food areas, behavioral learning, and location-guide to other species groups. Call-making in francolins is for communication especially in territorial marking and defense against species rivalry. Nevertheless, francolin calls seem not only to benefit the francolin bird communities but are prominently useful in environmental timing to the human community in Mamfe municipality and other parts of Cameroon. These calls are sometimes very alarming especially during the early hours of the day alerting the local crop-farmers upon the new day, and its activity engagement preparations.

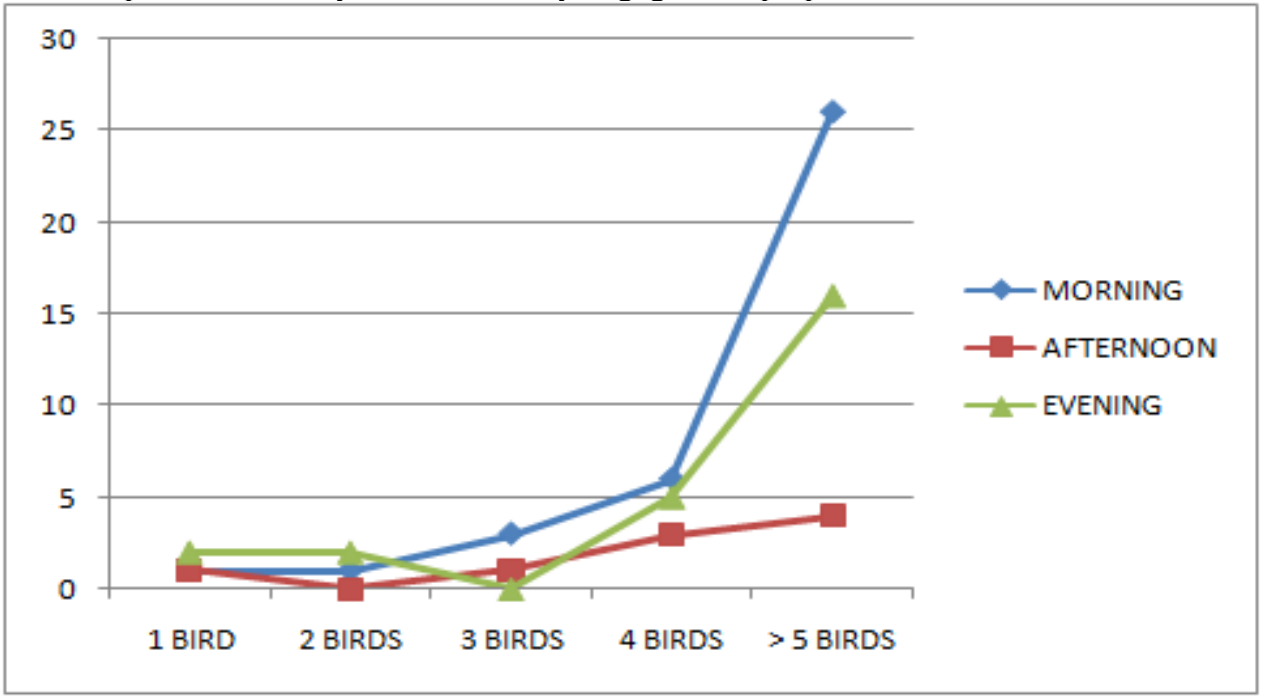

Figure 2: The bird number and day-period

Vocalization time and vocalization frequency showed a significant link, $\chi^{2}=6.834 \mathrm{df}=8 \mathrm{P}<0.05$ (fig.3). The calls made by this bird species are also time-specific, giving the birds a serious research attraction in the wildlife domain. The question would be that, why are these calls made at specific periods of the day. However, a comprehensive ecological study of this bird species could give an understanding on the call-timing. In this study it was discovered that, the calls were most frequent at the early hours of the day, between 3:00am-6:00am. The call frequency was prominently high during the fourth and the fifth hours of the day. The inhabitants of this municipality, especially the illiterate class knows the high call-frequency of francolin birds indicates this period of the day. Hence, preparation for the day activity engagement starts, especially for farmers whose crop-farms are far from the villages and would have to trek for hours to reach them.

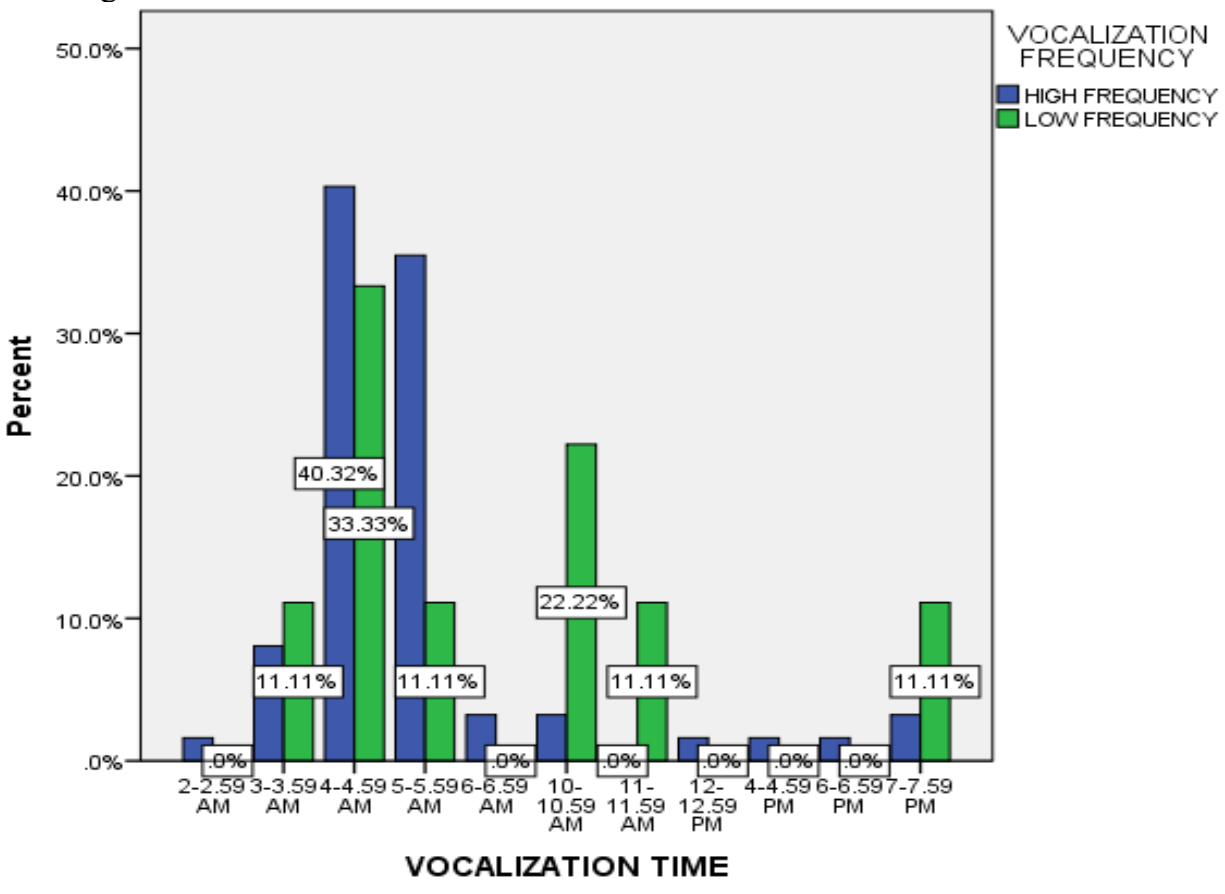

Figure 3: Vocalization time and frequency 
The day-period and bird number associated significantly, $\chi^{2}=51.278 \mathrm{df}=44 \mathrm{P}<0.05$ (fig.4). The social behavior of francolin birds generated a high call frequency, peaking between 4:00am-6:00am. This survey observed that the calls made by a single bird were generated at a low frequency rate as compared to that made by many birds in the area. This period of the day witnessed more high frequency calls, but grew weaker towards the $6^{\text {th }}$ hour of the day. It was also discovered that calls from larger francolin groups were more intensive and frequent and could be comparatively heard distantly. Similar results were obtained from the association of bird population and vocalization frequency, $\chi^{2}=21.294 \mathrm{df}=4 \mathrm{P}=0.000$ (fig.5).

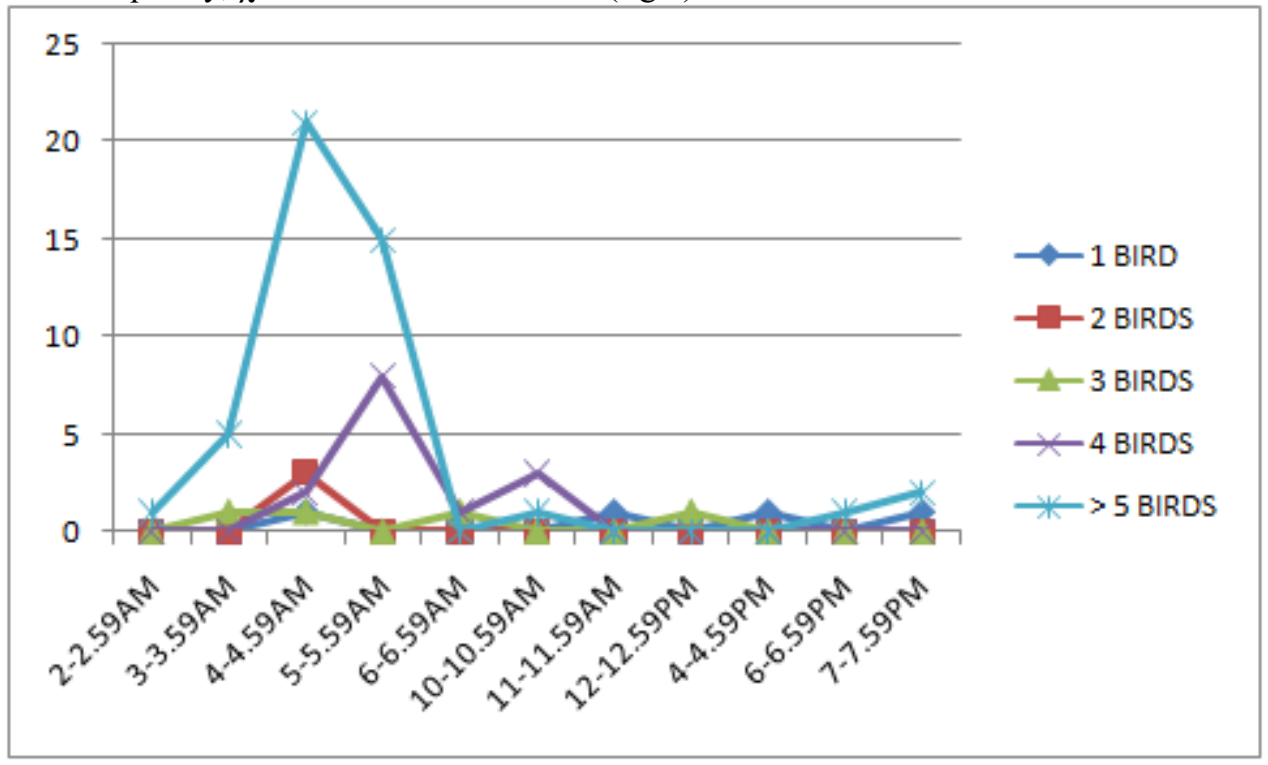

Figure 4: Bird number and day-period

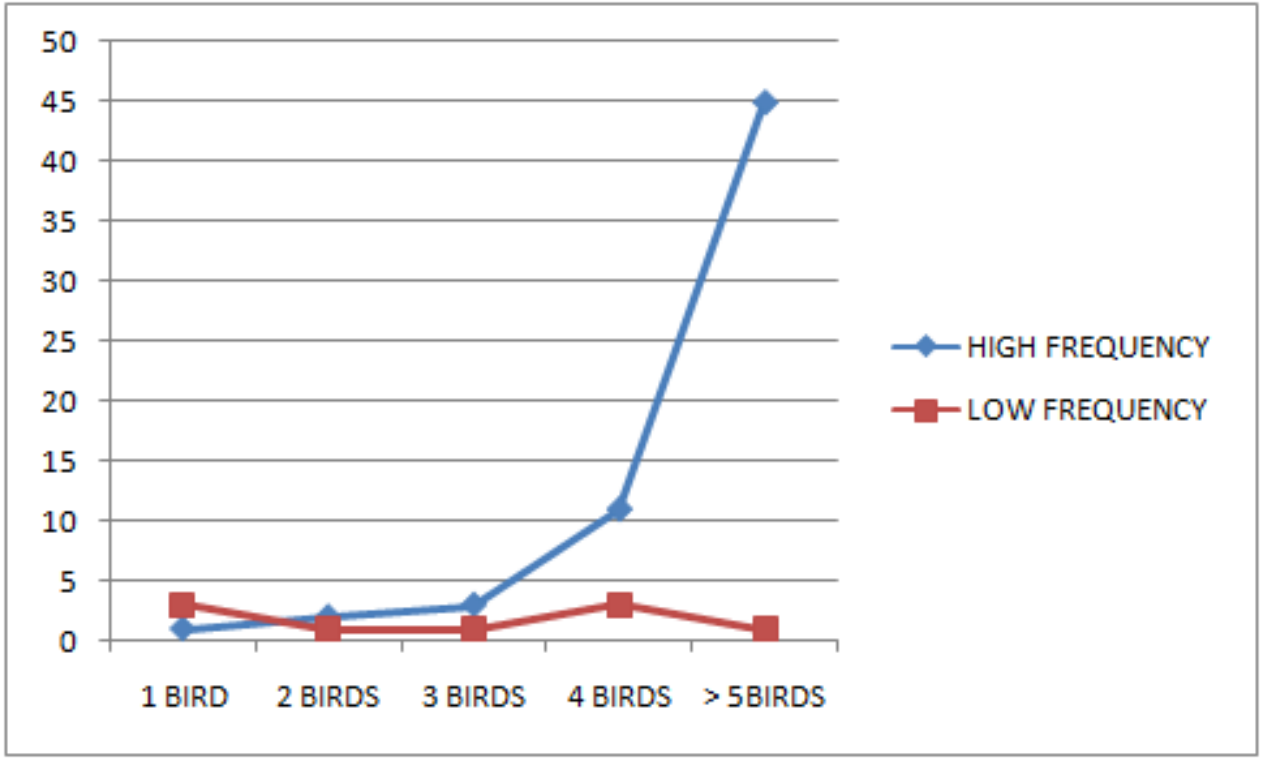

Figure 5: Bird number and vocalization frequency

Francolin number showed a call association frequency and intensity as revealed by the study. The bird number was proportionate to call frequency and intensity, 5 birds and above generated a call frequency of 64.79\% (fig.6). The vocalization frequency and intensity has been observed in primates groups such as chimpanzees, with larger groups generating intensive calls than smaller groups. 


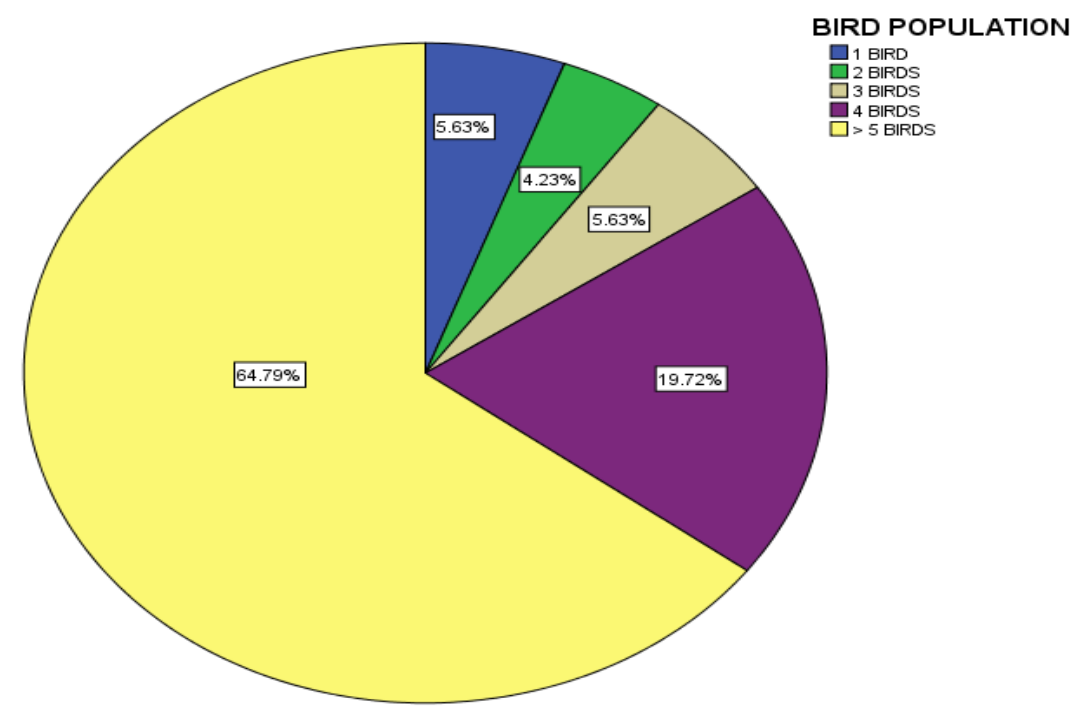

Figure 6: Bird number

Additionally, cropland showed a significant correlation with bird population, $\mathrm{r}=0.244 \mathrm{P}<0.05$ (fig.7). The bird group size witnessed an influence on the call location, with more calls from cropland (70.42\%) than the forest areas (29.58\%) (fig.8). Francolin birds are crop-pest in Cameroon, destructive to cereals and tubers, and are among the bird species that have rendered crop-cultivation difficult in some parts of the country where their number is high. These birds have been hunted for consumption by the local population, partly because of their pest behavior, accounting for serious crop-loss in some communities and also for income. Though, francolin birds play a role in local time indication to the local community in these areas, their crop-destruction behavior needs a conservation attention. Many villagers complained the bird species is a nightmare to crop cultivation, forcing some farmers to sort for weaver-bird combat strategies, such as bird stoning, trapping, scarecrow-mounting, and catapult-killings to reduce its population.

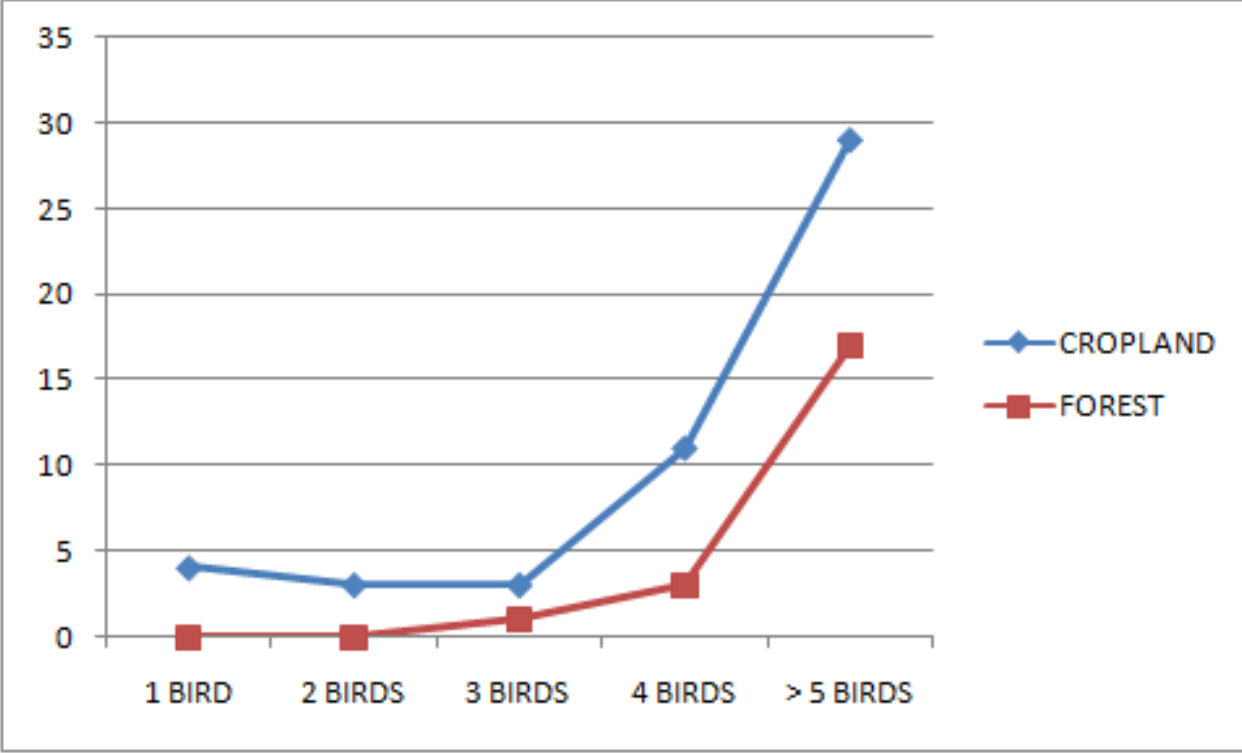

Figure 7: Bird number and vocalization location 


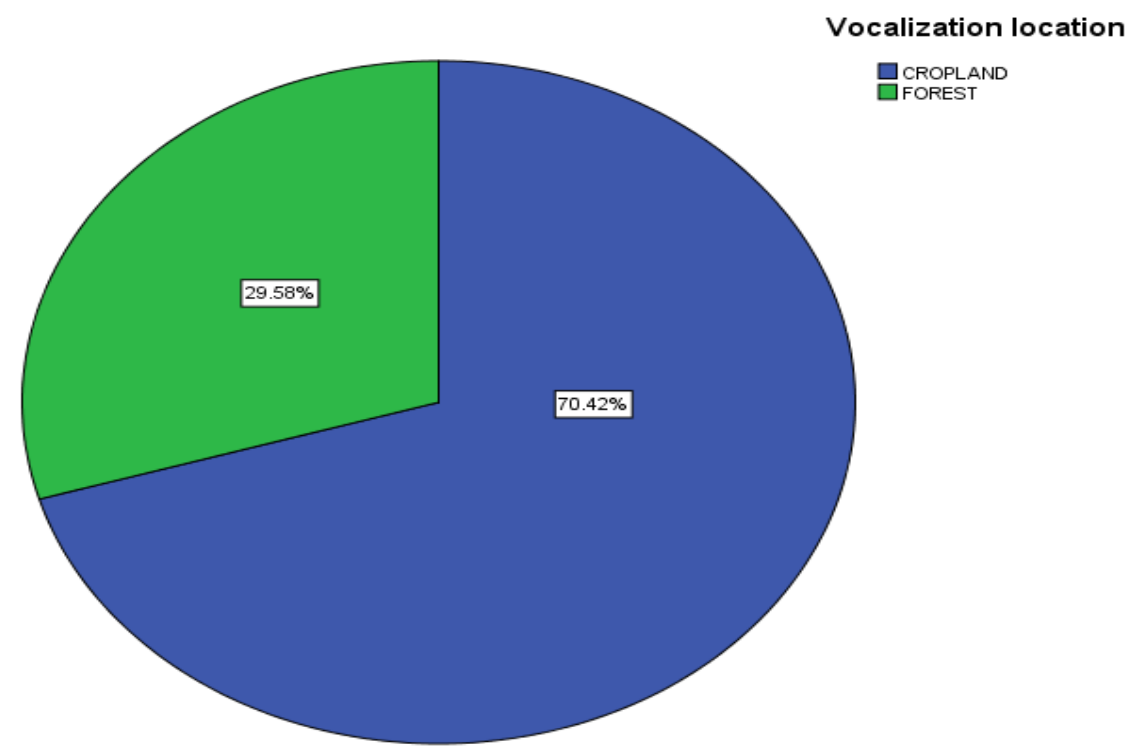

Figure 8: Vocalization location

\section{DISCUSSION}

Avian vocalizations can have intra-specific and/or inter-specific functions such as communication alarm, resource location, pair-bond maintenance, territory defense, and mate attraction (Searcy and Andersson 1986, Marler 2004, Catchpole and Slater 2008). The majority of these studies, however, have focused on daytime vocalizations by diurnal birds. Nocturnal vocalizations are traditionally associated with nocturnal and crepuscular birds such as owls and nightjars (Jacot 1931, Appleby and Redpath 1997, Woodin et al. 2000), and this study confirms that the strigiformes and caprimulgiformes contain high percentages of nocturnally vocalizing species. These birds' nocturnal vocalizations are largely associated with regular activities such as mating and courtship that occur at night (Martin 1973, Lundberg 1980, Cink 2002). Consequently, these nocturnal vocalizations are considered to function in a way similar to the daytime vocalizations of diurnal birds.

The prevalence of nocturnal vocalizations may have implications for conservation surveys and species detection. Surveys are often restricted to dawn or daylight (Ralph et al. 1995, Francis et al. 2009), which implies that a number of species that vocalize primarily at night may remain undetected or be misinterpreted. When the occurrence and regularity of nocturnal vocalizations across different taxonomic groups are established, sampling regimes may be adjusted to increase likelihood of detection. Nocturnal vocalizations in francolins may function inter-sexually or intra-sexually. Like dawn vocalizations, vocalizing at night often occurs with the onset of the breeding season before females arrive in some species of birds. This is when territory acquisition and maintenance by males may incite nocturnal vocalizations (Staicer et al. 1996), indicating an intra-sexual function. Nocturnal vocalizations also occur later in the breeding season, when mate attraction and pair bonding occur (Catchpole and Slater 2008), indicating an intersexual function. The function of nocturnal vocalizations likely varies by species. In some species, vocalizing at night may be a by-product of artificial light conditions (Miskell and Justice 2001, Hill et al. 2005), while in others nocturnal vocalizations are influenced by mated status (Tyler and Green 1996). A species may use nocturnal vocalizations for different purposes throughout the year. For example, early in the breeding season male common nightingales may vocalize nocturnally to attract mates, later in the season to reproductively stimulate or guard their females (Amrhein et al. 2002). Nocturnal vocalizations in a single species may be supported by multiple hypotheses. For example, the grasshopper sparrow's nocturnal vocalizations are largely pair-bond vocalizations (Vickery 1996), which are more complex than territorial vocalizations that are produced during the day (Smith 1959).

Vocalizing at night is taxonomically widespread, occurring in at least $30 \%$ of 749 breeding birds in North America. Lack of significant phylogenetic signal indicates that nocturnal vocalizations are not simply the result of phytogeny and may be instead promoted by ecological factors. It is important to note, however, that the detection of a species' nocturnal vocalizations may be influenced by differences in research effort among families and orders. Consequently, nocturnal vocalizations may be more widespread than this number of confirmed accounts because of insufficient data or lack of publication about each species' pattern of daily vocalization. How often birds vocalize at night varies by species. For example, birds such as the common loon and yellow-breasted chat vocalize at night regularly, while others such as the wood thrush (Hylocichla mustelina) and indigo bunting (Passerina cyanea) do so rarely. Regular nocturnal vocalizations by diurnal birds may be explained by all hypotheses. For example, for the reproductive stimulation hypothesis, nocturnal vocalizations can be expected regularly just prior to egg laying 
(Amrhein et al. 2002) but not during the rest of the breeding season. Occasional and rare nocturnal vocalizations can be explained by the hypotheses of elevated light conditions, reduced acoustic competition, and mate attraction. More specifically, birds with lower retinal sensitivity may be able to detect light only on nights with a full moon, which can promote occasional or rare nocturnal vocalizations. Similarly, birds may choose to vocalize occasionally at night when daytime noise is above a certain threshold, which may occur infrequently. Lastly, a male may occasionally vocalize at night to attract extra-pair females, if on occasion, he detects unpaired females in the area.

\section{CONCLUSION}

The human population increase in countries such as Cameroon has been the major reason for encroachment into the wildlife habitat, causing the decline of many wildlife populations and species extirpation. The environmental indication role of wildlife, especially the birds is well known, however, the week implementation of conservation laws and measures has witnessed a serious set-back to wildlife population management in Cameroon. Conservation projects to enhance the management strategies of game birds such as francolins that are very important to local time indication to illiterate human population in remote areas of the country are absent. The hunting of francolin birds for bush-meat consumption is another contributor to its population decline. This bird species, as other wildlife is considered to be a source of protein to many people living in remote communities like Mamfe, hence, trapsetting is believed to be the main strategy used to harvest the bird population from the wild. In this study francolin birds were more located in cropland where they serve as pest destroying cereals and tubers, a conflict that has caused annual crop-yield declines in most parts of Cameroon where these birds are common. This study recommends a comprehensive ecological study on the bird population distribution, feeding strategies, home range, and ex-situ conservation programs.

\section{REFERENCE}

Amrhein , V Korner , P. and Naguib M. (2002). Nocturnal and diurnal singing activity in the Nightingale: correlations with mating status and breeding cycle. Animal Behaviour 64:939-944.

Appleby , B. M. and Redpath S. M. (1997). Indicators of male quality in the hoots of Tawny Owls (Strix aluco). Journal of Raptor Research 31:65-70.

Boncoraglio, G. \& Nicola Saino (2007). "Habitat structure and the evolution of bird song: a meta-analysis of the evidence for the acoustic adaptation hypothesis". Functional Ecology. 21: 134-142. doi:10.1111/j.13652435.2006.01207.x.

Bostwick, Kimberly S. \& Richard O. Prum (2003). "High-speed video analysis of wing-snapping in two manakin clades (Pipridae: Aves)". The Journal of Experimental Biology. 206 (Pt 20): 3693-3706. doi:10.1242/jeb.00598. PMID 12966061.

Buckland, S.T., D.R. Anderson, K.P. Burnham, J.L. Laake, D.L. Borchers \& L. Thomas (2004). Advanced Distance Sampling. Oxford University Press, London, England, 416pp.

Catchpole , C. K. and P. J. B. Slater (2008). Bird song: biological themes and variations, 2nd ed. Cambridge University Press, New York.

Cink C. L. (2002). Whip-poor-will (Caprimulgus vociferus), no 620. In A. Poole and F. Gill [EDS.], The birds of North America. Birds of North America, Inc., Philadelphia.

Coles RB; Konishi M \& Pettigrew JD (1987). "Hearing and echolocation in the Australian Grey Swiftlet, Collocalia spodiopygia". J. Exp. Biol. 129: 365-371.

Derryberry, Elizabeth (2009). "Ecology Shapes Birdsong Evolution: Variation in Morphology and Habitat Explains Variation in White-Crowned Sparrow Song". The American Naturalist. 174 (1): $24-33$. doi:10.1086/599298. PMID 19441960.

Dickinson, E. (2003). The Howard and Moore Complete Checklist of the Birds of the World. Christopher Helm, London, UK.

Ehrlich, Paul R.; David S. Dobkin \& Darryl Wheye (2008). Bird Voices and Vocal Development from Birds of Stanford essays. Retrieved 9 Sep.

Ey, Elodie; Fischer, J. (2012). "The "acoustic adaptation hypothesis" - a review of the evidence from birds, anurans and mammals". Bioacoustics. 19 (1-2): 21-48. doi:10.1080/09524622.2009.9753613.

Francis , C. M. Blancher, P. J. and R. D. Phoenix (2009). Bird monitoring programs in Ontario: what have we got and what do we need? Forestry Chronicle 85:202-217.

Goodale, E. \& Kotagama, S. W. (2005). "Testing the roles of species in mixed-species bird flocks of a Sri Lankan rain forest". Journal of Tropical Ecology. 21 (6): 669-676. doi:10.1017/S0266467405002609.

Halfwerk, Wouter; Holleman, L.J.M.; Lessells, C.M.; Slabbekoorn, H. (2011). "Negative impact of traffic nosie on avian reproductive success". Journal of Applied Ecology. 48 (1): 210-219. doi:10.1111/j.13652664.2010.01914.x.

Hartshorne, Charles (1958)."Some Biological Principles Applicable to Song Behavior" in The Wilson Bulletin Vol. 70, No. 1 pp. 41-56 
Henrik Brumm (2004). "The impact of environmental noise on song amplitude in a territorial bird". Journal of Animal Ecology. 73 (3): 434-440. doi:10.1111/j.0021-8790.2004.00814.x.

Hill , C. E.; Copenhaver, K. A. Gangler, R. K. and J. W. Whaley (2005). Does light intensity influence song output by Northern Mockingbirds? Chat 69:61-67.

Howell, Steve N. G. \& Sophie Webb (1995). A Guide to the Birds of Mexico and Northern Central America. Oxford University Press. ISBN 978-0-19-854012-0.

Islam, K. (1999). Erckel's Francolin (Francolinus erckelii), Black Francolin (Francolinus francolinus), Grey Francolin (Francolinus pondicerianus). The Birds of North America, 394-396.

Jacot E. C. (1931). Notes on the Spotted and Flammulated Screech Owls in Arizona. Condor 33:8-11.

Johnsgard, P. (1999). The Pheasants of the world. Biology and Natural History, Smithsonian Institute press. Washington, D. C, U.S.A.

Kelley, L. A.; Coe, R. L.; Madden, J. R.; Healy, S. D. (2008). "Vocal mimicry in songbirds". Animal Behaviour. 76 (3): 521-528. doi:10.1016/j.anbehav.2008.04.012.

Krause, Bernard L. (1993). "The Niche Hypothesis" (PDF). The Soundscape Newsletter. 06. Archived from the original (PDF) on 2008-03-07.

Lieser M; P. Berthold1 \& G. A. Manley (2005). "Infrasound in the capercaillie (Tetrao urogallus)". Journal of Ornithology. 146 (4): 395-398. doi:10.1007/s10336-005-0003-y.

Lundberg A. (1980). Vocalizations and courtship feeding in the Ural Owl (Strix uralensis). Ornis Scandinavica 11:65-70.

Luther, David A.; Derryberry, E.P. (2012). "Birdsongs keep pace with city life: changes in song over time in an urban songbird affects communication". Animal Behaviour. 83 (4): 1059-1066. doi:10.1016/j.anbehav.2012.01.034.

Madge, S. and P. McGowan. (2002). Pheasants, Partridges, and Grouse: A guide to the pheasants, partridges, quails, grouse, guineafowl, buttonquails and sandgrouse of the world. Chirstopher Helm London, UK.

Manfe Rual Council (2012). The National Community Driven Development Program

Manson-Barr, P. and Pye, J. D. (1985). Mechanical sounds. In A Dictionary of Birds (ed. B. Campbell and E. Lack), pp. 342-344. Staffordshire: Poyser.

Marler P. (2004). Bird calls: their potential for behavioural neurobiology. Annals of the New York Academy of Sciences 1016:31-44.

Marler, Peter; Hans Willem Slabbekoorn (2004). Nature's music: the science of birdsong. Academic Press. p. 145. ISBN 978-0-12-473070-0.

Martin D. J. (1973). Selected aspects of Burrowing Owl ecology and behavior. Condor 75:446-456.

Miskell , K. A. and M. J. Justice (2001). Nocturnally singing mockingbirds orient towards lights. Chat 65:1-6.

Møller AP; J. Erritzøe; L. Z. Garamszegi (2005). "Covariation between brain size and immunity in birds: implications for brain size evolution" (PDF). Journal of Evolutionary Biology. 18 (1): $223-237$. doi:10.1111/j.1420-9101.2004.00805.x. PMID 15669979.

Morton, E.S. (1975). "Ecological sources of selection on avian sounds". American Naturalist. 109 (965): $17-34$. doi:10.1086/282971.

Payne, R. (2000). Birds of the World, Biology 532, Recent Families, Birds of the World online download on march 16, 2004 http://www.ummz.Isa.umich- edu Payne, R. 2000. Birds of the World,

Olson, Christopher R.; Fernández-Vargas, Marcela; Portfors, Christine V.; Mello, Claudio V. (2018). "Black Jacobin hummingbirds vocalize above the known hearing range of birds". Current Biology. 28 (5): R204R205. doi:10.1016/j.cub.2018.01.041. PMID 29510104.

Pomeroy, D. and E. Abe. (1992). The distribution and abundance of gamebirds in Africa with special reference to the East Africa francolinus (Francolinus spp.) In: Gibier Faune Sauvage 9 (Birkan, M., G. R. Potts, N. J. Aebischer and S. D. Dowell, (Eds) Perdix IV, First Intl. Symp. On Partridge, Quails and Francolins, Fordingbirdge, Hampshire, U. K. pp. $527-537$.

Ralph , C. J. Sauer, J. R. and S. Droege [EDS.]. (1995). Monitoring bird populations by point counts. United States Forest Service General Technical Report PSW-GTR-149.

Searcy, W. A. and M. Andersson (1986). Sexual selection and the evolution of song. Annual Review of Ecology and Systematics 17:507-533.

Slabbekoorn, H. \& Peet, M. (2003). "Birds sing at a higher pitch in urban noise". Nature. 424 (6946): 267. doi:10.1038/424267a. PMID 12867967.

Slabbekoorn, Hans; Ellers, Jacintha; Smith, Thomas B. (2002). "Birdsong and sound transmission: the benefits of reverberations" (PDF). The Condor. 104 (3): 564-573. doi:10.1650/00105422(2002)104[0564:basttb]2.0.co;2.

Slater Peter J. B., Mann Nigel I. (2004). "Why do the females of many bird species sing in the tropics?". Journal of Avian Biology. 35 (4): 289-294. doi:10.1111/j.0908-8857.2004.03392.x.

Smith R. L. (1959). The songs of the Grasshopper Sparrow. Wilson Bulletin 71:141-152. 
Staicer, C. A; Spector , D. A and A. G. Horn (1996). The dawn chorus and other diel patterns of acoustic signaling, p. 426-453. In D. E. Kroodsma and E. H. Miller [EDS.] , Ecology and evolution of acoustic communication in birds. Cornell University Press, New York.

Suthers R. A \& Hector D.H (1982). "Mechanism for the production of echolocating clicks by the Grey Swiftlet, Collocalia spodiopygia". J. Comp. Physiol. A. 148 (4): 457-470. doi:10.1007/BF00619784.

Thomas D.M (1988). Status and Conservation of Takamanda Gorilla, WWF Report.

Thomas, L., S.T Buckland, E.A. Rexstad, J.L. Laake, S. Strindberg, S.L. Hedley, J.R.B. Bishop, T.A. Marques \& K.P. Burnham (2010). Distance software: design and analysis of distance sampling surveys for estimating population size. Journal of Applied Ecology 47: 5-14.

Tubaro, Pablo L.; Segura, Enrique T. (1994). "Dialect Differences in the Song of Zonotrichia capensis in the Southern Pampas: A Test of the Acoustic Adaptation Hypothesis". The Condor. 96 (4): 1084-1088. doi:10.2307/1369117. JSTOR 1369117.

Tyler, G. A. and R. E. Green (1996). The incidence of nocturnal song by male Corncrakes Crex crex is reduced during pairing. Bird Study 43:214-219.

Vickery P. D. (1996). Grasshopper Sparrow (Ammodramus savannarum). In A. Poole and F. Gill [EDS.], The birds of North America. Academy of Natural Sciences, Philadelphia.

Woodin , M. C; Skoruppa , M. K. and G. C. Hickman . (2000). Surveys of night birds along the Rio Grande in Webb County, Texas. Final report. United States Fish and Wildlife Service, Corpus Christi, TX. 